\title{
CLINICAL TESTING OF NEW DRUGS IN THE UNITED STATES
}

$\mathrm{R}$ EGULATIONS strengthening control over the testing of new drugs in clinical trials have been approved by the U.S. Department of Health, Education and Welfare. The new regulations would require: that the Food and Drug Administration be given the full details about the distribution of drugs for investigation; that clinical investigations be based on adequate pre-clinical studies to assure safety; and that the clinical investigations themselves be properly planned, executed by qualified investigators, and that the Food and Drug Administration authority be kept fully informed during the progress of the investigations.

The present regulations require that drugs used in clinical trials be labelled for "investigational use" only and that manufacturers keep records of distribution. The regulations also require that investigators have adequate facilities, and that names of investigators be made available to the Food and Drug Administration on request.

Existing regulations, however, do not require either an initial notice to the Food and Drug Administration of a clinical trial of a new drug or subsequent reports on such use. Now, once a clinical investigation has been undertaken, if a substantial doubt developed as to the safety of the drug, the Food and Drug Administration and all investigators using the drug would be notified immediately. If necessary, the trial would be halted by the Administration. Similarly, if a plan proved to be inadequate to assure safety, or if the plan as presented was not being followed, the Administration could require corrective action and would, if necessary, terminate the work.

In notifying the Food and Drug Administration of his intention to begin a clinical investigation with a new drug, a manufacturer would be required to provide information concerning all the pre-clinical investigations, including experimental trials which had been undertaken with animals, to show that it is reasonably safe to test the drug on human patients. Where the clinical investigation involves use on infants or pregnant women, special assurances of safety for such use would be required; copies of the complete information about the pre-clinical investigation and experience with the drug which will be supplied to each investigator, including all that is known about the relevant side effects and precautions suggested by the pre-clinical data; and the names and a summary of the training and experience of each person who will participate in the investigations and an outline of what is planned in the clinical trials, how long they will take, how many patients will be involved, and when progress reports will be made.

Once an investigation was undertaken, the sponsors would be required to maintain complete records covering the distribution of the drug being investigated, and monitor the progress of the investigation.

Each investigator in the clinical trial would be required to supply the sponsor with a full statement of his education and experience, a description of the hospital, institutional and laboratory facilities available to him, and an outline of the plan that he intends to follow. He must fully inform himself about all the pre-clinical investigations before giving the drug to any patient, maintain complete records of his disposition of the drug and case-histories of the patients to whom it is administered, and furnish adequate reports to the sponsor promptly after the completion of the clinical trials. These records must be open to inspection by the Food and Drug Administration on request.

The proposed regulations were published with an invitation for all interested persons to comment within 60 days. Copies of the full regulations are available from the Commissioner of Food and Drugs, U.S. Department of Health, Education and Welfare, Washington 25, D.C.

\section{LIBRARIES AND PUBLIC SERVICES}

T HE annual conference of the Library Association at Llandudno, September 25-28, was the first annual conference to be held since the Association was transformed into a purely professional body, but although the president, Mr. W. B. Paton, considered the implications of this change in his presidential address, "The Profession of Librarianship", the proceedings otherwise presented fewer features of general scientifie interest than usual.

Mr. Paton boldly challenged the profession to tackle its objectives with unity and courage, particularly the problems involved in relating public libraries to the library service of the country as a whole, and attributed the failure of the Roberts Committee to face that problem to the negligence of the Library Association itself. His exposition of the professional ideal contains much that is to the point for any professional man or woman, whether in a particular section of the profession of librarianship or in any other profession. So, too, Mr. A. H. Bill's discussion on September 26 of the problems of the library in the community indicates ways in which readers themselves might co-operate in the development of a service which meets far more adequately and effectively the needs of to-day. However, in the first instance, he urges librarians themselves to discard the erroneous ideas that the public library is a collection of books and provides a service for various types of readers and to seek instead to develop the layout and arrangement of our libraries in accordance with the three-fold conception of their function and purpose. First, there is the provision of a community information service; secondly, that they act as a collection of information in various forms which has to be gathered, organized and fully exploited to be made fully and speedily available to every user; and thirdly, that the service given is to individuals, not to groups or types of readers. He believes that the public library could be a most potent means of achieving Dr. J. R. Oppenheimer's idea: "to keep our minds open and to keep them deep, to keep our sense of beauty and our ability to make it".

Mr. A. Duggan's stimulating annual locture, also on September 26, "Personal Experience and the 